\title{
Monitoring of the Heavy Metal Release During Waste Combustion
}

\author{
Quentin Falcoz, Daniel Gauthier', Stephane Abanades, Gilles Flamant \\ Processes, Materials, and Solar Energy Laboratory (CNRS-PROMES) \\ 7 Rue du Four Solaire, Odeillo, 66120 Font-Romeu - France
}

(Received December 20, 2008)

\begin{abstract}
A method for analyzing on-line the vaporized metals in an exhaust gas was developed by coupling an ICP (Inductively Coupled Plasma) spectrometer to the gas outlet of both a fixed bed reactor and a fluidized bed reactor. A calibration device was set up and implemented. It involves a standard gas synthesis protocol to obtain quantitative data. The calibration method was validated by heating Cd-spiked porous alumina particles in the fluidized bed. The mass of cadmium released from the solid phase was measured and compared to the amount of cadmium detected by the on-line gas monitoring system.

The versatile character of such a tool was demonstrated by case studies involving two types of wastes (municipal waste and sludge from water treatment plant) and two types of high temperature processes (fixed bed and fluidized bed).
\end{abstract}

Keywords: Continuous emission monitoring, ICPOES, calibration, metal vaporization, high temperature processes.

\section{INTRODUCTION}

Municipal solid waste incineration processes are expected to develop in the next decades, since they simultaneously permit a great reduction of waste volume (about $90 \%$ ) and power generation. Thermal treatment is an effective method of remediating the municipal solid waste, and major environmental concerns are both the emissions of toxic metals in the fumes and their possible leaching from the different solid incineration residues. During any waste thermal treatment, organic matrices burn and the metals' concentration in the exhaust gas is the only information available. Consequently, monitoring the continuous gaseous emissions of metallic pollutants is essential to study their behavior under these conditions.

On-line pollutant analysis methods in gaseous phase iritend to measure the species' concentration, continuously or semi-continuously. Such methods are irteresting in the global concern of risk prevention because they may permit a quick detection of hazards, thus an appropriate reaction. Besides, the development of reliable and reproductive concentration measurement processes will possibly lead to new gaseous emission regulations: for instance, current regulations concerning heavy metals' release in fumes deal with their cumulative measurement over several hours since no continuous analysis technique exists. If such a technique comes to the market, regulations will clearly evolve based on it.

PEARLS (Plasma Excited Atomic Resonance Line Spectroscopy) process was first developed for alkali measurements, then applied to heavy metal analysis $/ 1$. The LIBS method (Laser Induced Breakdown Spectroscopy), also known as Laser Spark Spectroscopy, uses a high-energy focused laser to create a plasma in the measurement volume. Bucley et al. 12/

\footnotetext{
"Daniel Gauthier: phone : +33 468307 757, fax : +33468302 940, e-mail : gauthier@promes.cnrs.fr
} 
applied LIBS successfully to measure heavy metal $(\mathrm{Cd}$, $\mathrm{Cr}, \mathrm{Hg}$ and $\mathrm{Pb}$ ) traces under incinerator conditions. Before them, Neuhauser et al. /3/ developed a quasicontinuous on-line measurement system - so-called LIPS, for Laser-Induced Plasma Spectroscopy - by coupling a LIBS process with an automated in-line filter sampling. Woskov et al. /4/ worked with a microwave plasma and atomic emission spectroscopy. In this case, the main advantage is that the plasma is directly created from the gas to analyze. Helou /5/ was the first to use and develop ICP (Inductively Coupled Plasma) spectrometry. In such a system, the gas to analyze is extracted and led via a nebulizer into an argon plasma. The system was calibrated by nebulizing (ultrasonic nebulizer) a standard solution of metal. Trassy et al. /6/ improved Hélou's method by using a more accurate calibration. They carried out a double sampling technique: first sampling at high flow rate to ensure isokinetism, then second sampling at low flow rate to permit the analysis by ICP.

The on-line metal analysis method presented here is based on ICP spectrometry. Poole et al. /7/ used ICPOES to study temporal variations of metal concentrations in the flue gas of a waste-to-energy pilot plant. It was also implemented at laboratory scale by our own group in order to study the kinetics of metal release $18,9 /$ and first results were only qualitative. This paper is focused on the description of the on-line analysis method and its use for quantifying heavy metal vaporization during different waste thermal treatments. Combustion of sludge in a fluidized bed and combustion of model waste in both a fluidized bed and a fixed bed are presented in a case study. It shows that the developed method can be applied to various kinds of waste under various combustion conditions.

\section{EXPERIMENTAL SET-UP}

\subsection{On-line gas analysis system}

The ICP spectrometer (Horiba Jobin Yvon JY 38S), classically used for liquid analysis, was adapted to allow the gas injection in the argon plasma. The global gas flow rate must be high enough to "pierce" the plasma. The sample cannot penetrate the plasma if the injection flow rate is too low, and it is rejected to its periphery, thus leading to wrong analytical results. The gas velocity must be increased without increasing the global flow rate since the plasma torch power limits the admissible flow of foreign gas. This is achieved by reducing the injector internal diameter to its half ( 1.5 $\mathrm{mm}$ I.D.), which increases the gas velocity fourfold.

Calibration is the main problem to be solved in order to analyze on-line by ICP-OES a metal contained in a gas phase. Indeed, ICP spectrometry is conceived for analyzing liquid solutions, and any gas injection induces problems, whether during the calibration or during the analysis. Moreover, standard gases, which are required since ICP-OES is a comparative method, do not exist commercially and they have to be made from gaseous matrix as similar as possible to that of the samples. In the case of an aerosol, which is a polyphasic background, the physical form is hard to control. Therefore, the aerosol size distribution, the gas composition and the metal speciation should be as close as possible in the calibration gas as they are in the gas to be analyzed.

\subsection{Protocol of standard gas synthesis}

We developed a protocol inspired by Trassy et al.'s work 16/. Argon is used for the standard solution nebulization and the gas to be analyzed is added after the nebulization by the sheath argon canal. This system makes it possible to work with the optimum flow of nebulization gas, thus without disturbing the plasma stability, because in such a situation the nebulizing argon is not a foreign gas for the plasma.

The operating protocol is then (Figure 1):

- During calibration, a standard metal solution is nebulized with argon, and the "clean" gas (i.e. cadmium-free gas) is added after the nebulizer.

- During analysis, a pure water solution is nebulized with argon and the gas containing cadmium (gas to be analyzed) is added after the nebulizer.

Thus, the gas composition and the water content are rigorously identical in both cases, which is a strong advantage for such a comparative measurement method. 


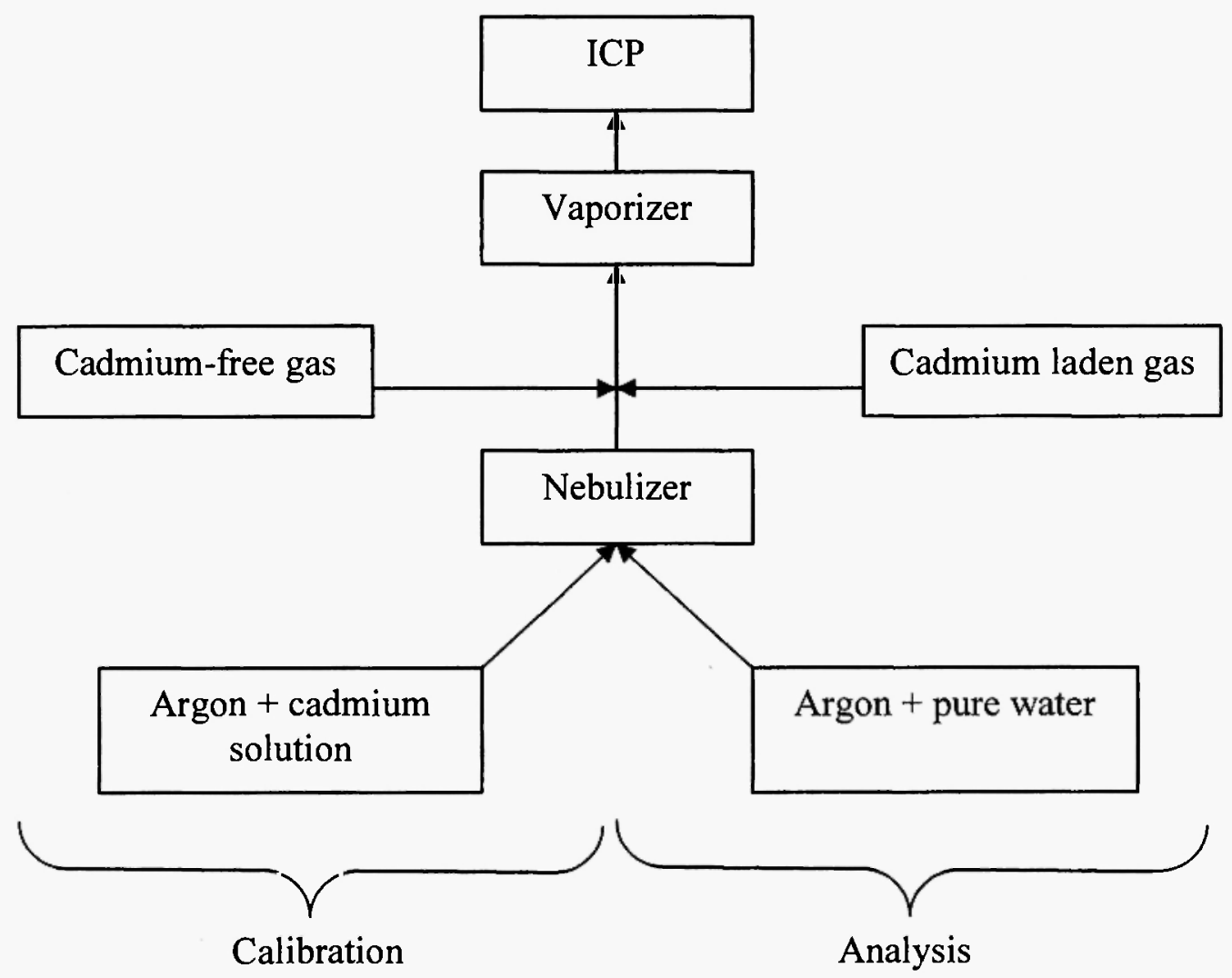

Fig. 1: Standard gas synthesis protocol ( $\mathrm{Cd}$ is used as an example)

\subsection{Fluidized bed reactor}

The experimental set-up is schemed in Figure 2. The high temperature reactor is a fluidized bed, made of AISI $316 \mathrm{~L}$ stainless steel, $4.510^{-3} \mathrm{~m}$ thick. It is a 0.105 $\mathrm{m}$ i.d. and $0.4 \mathrm{~m}$ high cylinder, topped by a $0.2 \mathrm{~m}$ disengaging height. The reactor is electrically heated by two half-cylinder radiative shells and insulated. The bed is composed of sand of mean diameter $0.710^{-3} \mathrm{~m}$ (bed mass: $1.6 \mathrm{~kg}$; initial bed height: $15.10^{-2} \mathrm{~m}$ ), in which a given mass of reactive metal-spiked particles is injected when the reactor is at thermal steady state.

The fluidizing gas is preheated through a series of two electrical resistances. The nearby ICP (distance: 6 $\mathrm{m}$ ) is connected to the gas outlet in order to measure continuously the metal concentration in exhaust gases. The gas to be analyzed (sample gas) is carried to the ICP through a heated and insulated tubing (temperature $\left.250^{\circ} \mathrm{C}\right)$.

\subsection{Fixed bed reactor}

A fixed bed was coupled to the on-line analysis system in order to study waste combustion under other conditions (low heating rate). The fixed bed reactor is schemed in Figure 3 and its characteristics are listed in Table 1 .

\section{Table 1}

Characteristics of the fixed bed reactor

\begin{tabular}{ccccc}
\hline $\begin{array}{c}\text { Internal } \\
\text { Diameter } \\
(\mathrm{mm})\end{array}$ & $\begin{array}{c}\text { Thickness } \\
(\mathrm{mm})\end{array}$ & $\begin{array}{c}\text { External } \\
\text { Diameter } \\
(\mathrm{mm})\end{array}$ & $\begin{array}{c}\text { Bed } \\
\text { Height } \\
(\mathrm{mm})\end{array}$ & $\begin{array}{c}\text { Mass } \\
\text { of } \\
\text { Sand } \\
(\mathrm{g})\end{array}$ \\
\hline 80 & 4.5 & 89 & 15 & 110 \\
\hline
\end{tabular}




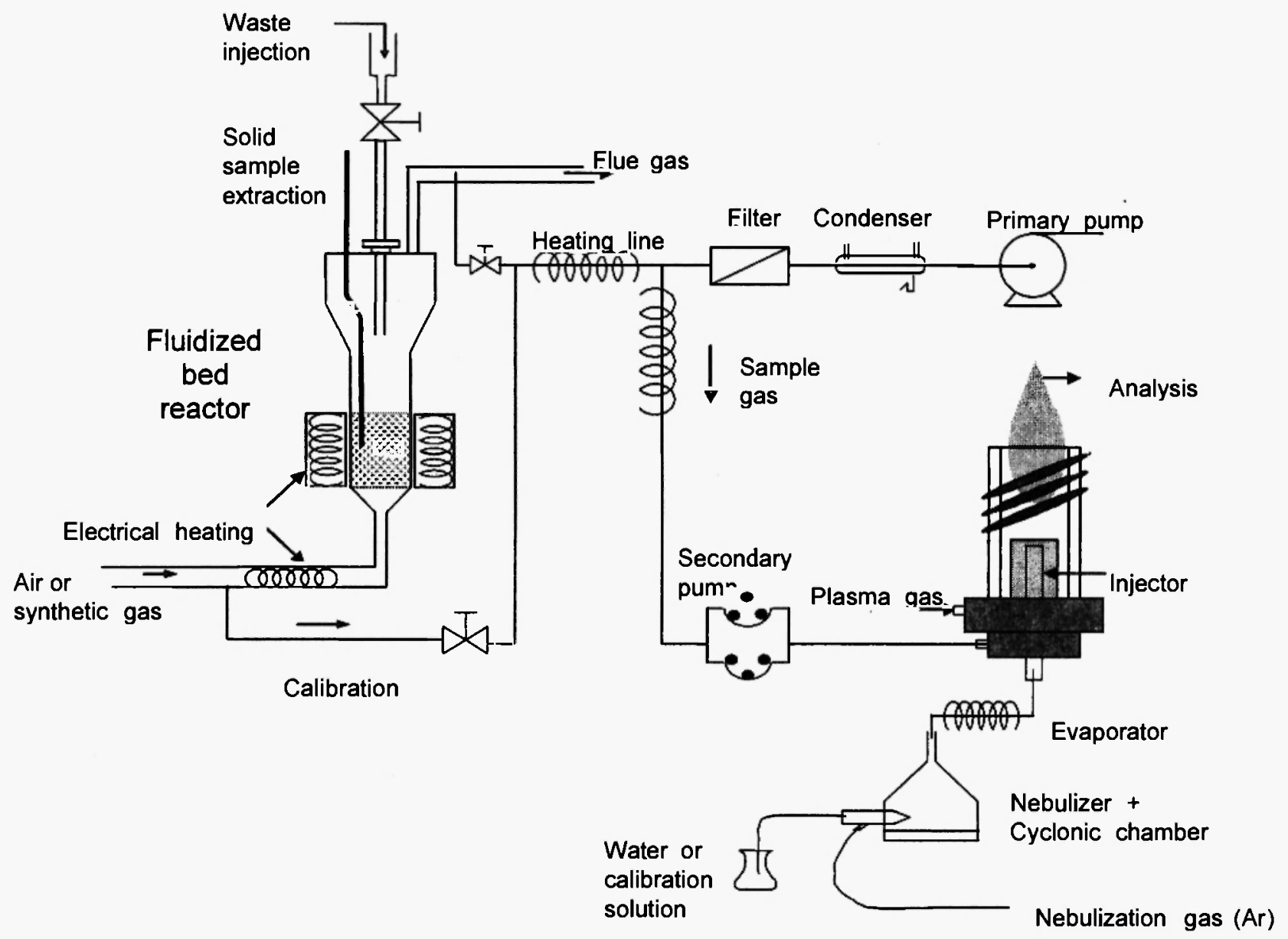

Fig. 2: Experimental set-up

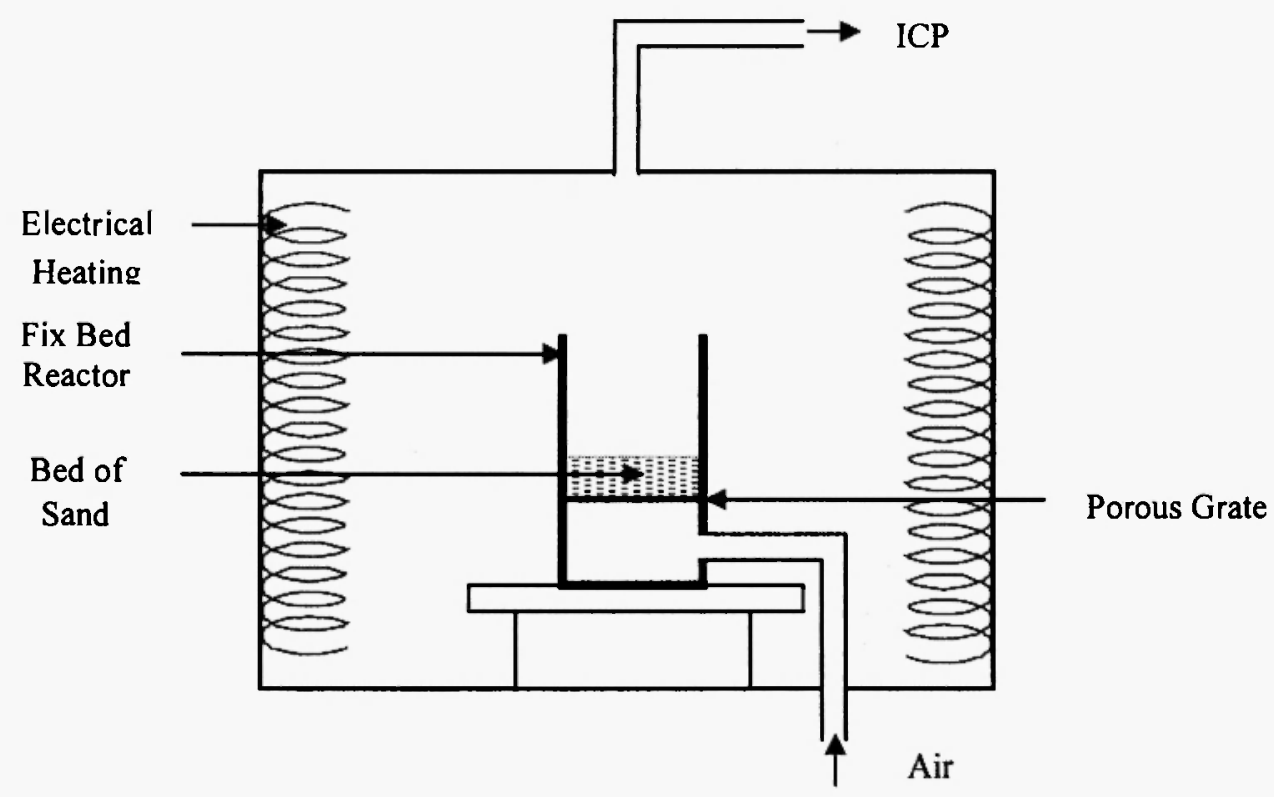

Fig. 3: Scheme of the fixed bed 
The bed is composed of sand and the samples are introduced into the bed before heating. The combustion gas (air) is introduced at the reactor basis. It is uniformly distributed through the bed sand by a porous stainless steel grate. The reactor is set inside a electrically-heated furnace and the temperature is measured inside the furnace.

\subsection{Validation of the analysis method}

A series of experiments was carried out to validate the calibration method /10/. First, Cd-spiked alumina particles were introduced in a hot fluidized bed and a $\mathrm{Cd}$ mass balance was performed on the reactor. The cadmium concentration in the gas phase was measured by the proposed on-line system, whereas the cadmium loss in the solid phase (i.e. Cd released from alumina particles) was obtained by classical ICP-OES analysis of acid-digested solid samples taken from the bed before and after the experiment. The Cd mass balance over the experiment duration was fairly good since $70 \%$ of the metal emitted from the alumina when injected in the hot fluidized bed was detected in the outlet gas by the ICP, and $10 \%$ are adsorbed on the sand particles. Some part of the metal probably never reaches the ICP torch (because of adsorption on sand particles and condensation along the sampling line), thus explaining partially the unbalance. Measurement uncertainties and detection limit of the spectroscopic method stand for the rest. Detection limits are respectively $6 \mu \mathrm{g} / \mathrm{m}^{3}, 11 \mu \mathrm{g} / \mathrm{m}^{3}$ and $16 \mu \mathrm{g} / \mathrm{m}^{3}$ for $\mathrm{Cd}, \mathrm{Pb}$ and $\mathrm{Zn}$.

\section{CASE STUDY}

The developed method was used to measure HM concentration during the combustion of different wastes, when no sample can be drawn from the reactor. The study is applied to the combustion of two matrices of waste (municipal waste and sludge) in two reactors (fluidized bed and fixed bed).

The composition of the municipal waste and of the sludge is given in Table 2 .
Table 2

Municipal waste and sludge composition (wt \%)

\begin{tabular}{ccccccc}
\hline & C & H & O & N & S & Ash \\
\hline $\begin{array}{c}\text { Municipal } \\
\text { Waste }\end{array}$ & 45.9 & 6.5 & 30.5 & 1 & 0.3 & 15.8 \\
Sludge & 45.2 & 5.0 & 41.9 & 6.2 & 0.6 & 1.1 \\
\hline
\end{tabular}

\subsection{Model waste combustion in a fluidized bed}

Experiments were carried out with a realistic artificial waste (RAW), recomposed from real waste. A special procedure was developed to elaborate spiked hơmogeneous particles suitable for fluidization. In this propedure, the waste (existing as flakes) is mixed with metal salt liquid solution, sand (diameter: $0.5 \mathrm{~mm}$ ), and wallpaper glue. The MSW/sand weight ratio is $1: 1$. Then, the mixture is shredded and pressed into cylindrical particles (diameter: $10 \mathrm{~mm}$, height: 6-12 $\mathrm{mm}$, density: $600 \mathrm{~kg} / \mathrm{m}^{3}$ ) using a hydraulic press, and finally dried.

Once the reactor was at steady state (desired temperature reached and operating conditions maintained), a given amount of RAW waste was injected into the bed. The time course of the metal concentration in exhaust gases was measured on-line by the adapted ICP-OES technique. With these burning particles, the initial metal concentration in the waste (qo) was measured by classical ICP spectrometry after acid digestion of particles. The quantitative results from the combustion at $800^{\circ} \mathrm{C}$ of model waste spiked with $\mathrm{Cd}, \mathrm{Pb}$ and $\mathrm{Zn}$ are plotted in Figure 4.

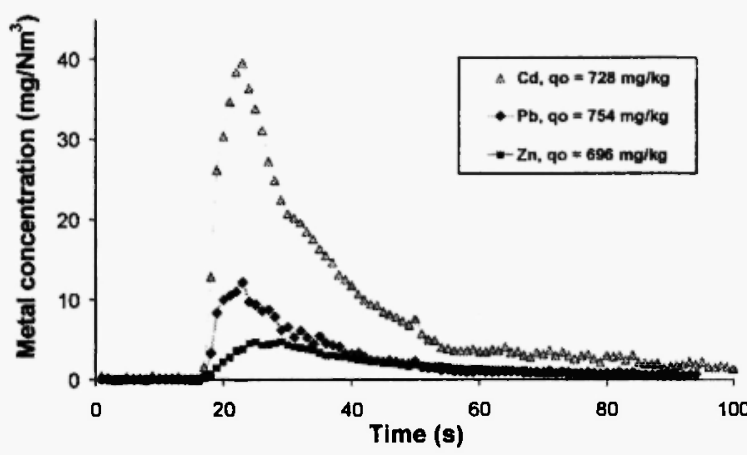

Fig. 4: Heavy metal analysis during model waste combustion in a fluidized bed at $800^{\circ} \mathrm{C}$ 
From Figure 4, it is possible to measure the area under the curves and thus to determine the final vaporization rate for each metal. After integration, the following values for the final vaporization rate were obtained: $72 \%$ for $\mathrm{Cd}, 48 \%$ for $\mathrm{Pb}$ and $38 \%$ for $\mathrm{Zn}$. These results are consistent and in good agreement with literature. Indeed, most previous works $/ 11,12 /$ found that the $\mathrm{HM}$ vaporization may be classified as: $\mathrm{Cd}>\mathrm{Pb}$ $>\mathrm{Zn}$.

\subsection{Sludge combustion in a fluidized bed}

Experiments were carried out with sludge particles introduced in the fluidized bed at $850^{\circ} \mathrm{C}$. The samples' preparation was similar to that in the case of model waste particles. The quantitative results from the combustion of sludge spiked with $\mathrm{Cd}, \mathrm{Pb}$ and $\mathrm{Zn}$ are plotted in Figure 5.

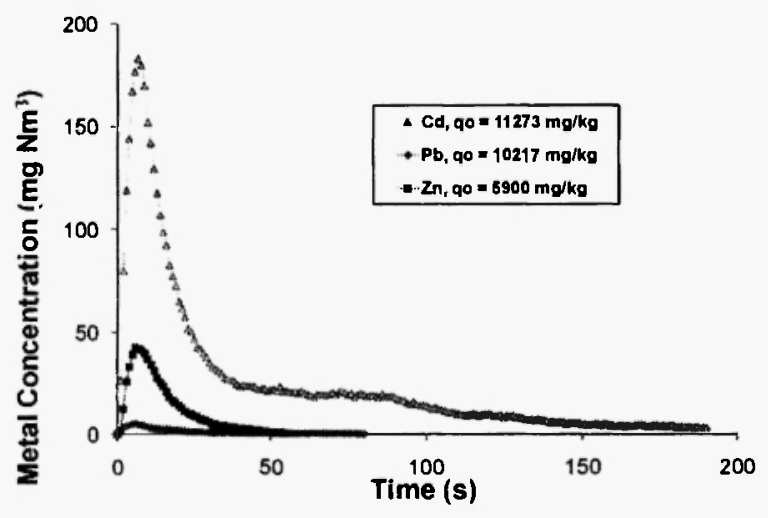

Fig. 5: Heavy metal analysis during sludge combustion in a fluidized bed at $850^{\circ} \mathrm{C}$

Corella et al. /13,14/ studied the partitioning of heavy metals during incineration of doped sludge. The cadmium vaporization from sludge was the most important, compared to the other studied metals. Our results from the analysis of $\mathrm{Cd}, \mathrm{Pb}$ and $\mathrm{Zn}$ release during sludge combustion are thus consistent with literature.

\subsection{Model waste combustion in a fixed bed}

Experiments were carried out with model waste samples spiked with $\mathrm{Cd}, \mathrm{Pb}$ or $\mathrm{Zn}$. For all experiments, the temperature increase rate was set at $0.5^{\circ} \mathrm{C} / \mathrm{s}$ between $20^{\circ} \mathrm{C}$ and $800^{\circ} \mathrm{C}$, then maintained equal to $800^{\circ} \mathrm{C}$. The air flow rate was set to $1 \mathrm{Nm}^{3} / \mathrm{h}$.

The temporal variations of the three studied heavy metals' concentrations and the temperature profile during the model waste combustion in fixed bed are plotted in Figure 6.

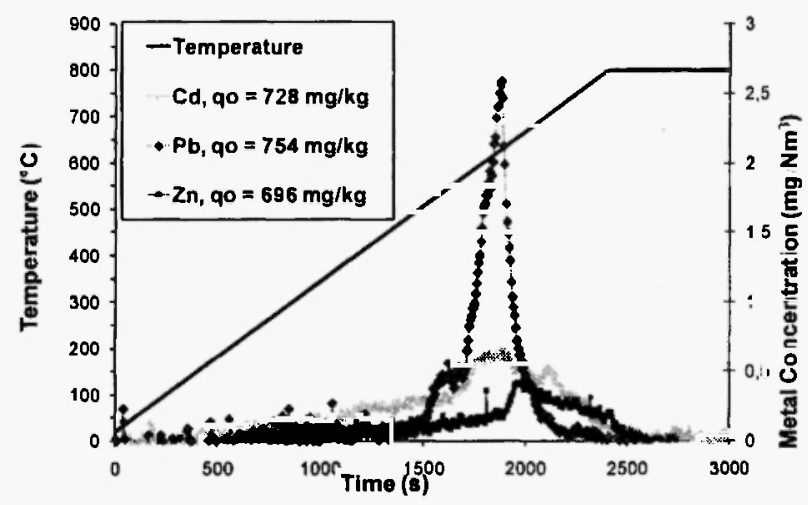

Fig. 6: Heavy metal analysis during model waste combustion in a fixed bed

In all cases, the metal's concentration in the outlet gas is maximal between $650^{\circ} \mathrm{C}$ and $700^{\circ} \mathrm{C}$. The vaporization is thus maximal in this temperature range.

Lead release occurs in two steps: first step around $450-500^{\circ} \mathrm{C}$, and second step, more important, from $580^{\circ} \mathrm{C}$ until the end of combustion. For $\mathrm{Zn}$ and $\mathrm{Cd}$, the first step is much less significant, and the second step starts at $550^{\circ} \mathrm{C}$ for $\mathrm{Cd}$ and at $650^{\circ} \mathrm{C}$ for $\mathrm{Zn}$. In the case of lead, the amount of particles injected in the fixed bed was more important $(8 \mathrm{~g}$ in $\mathrm{Pb}$ case, $2 \mathrm{~g}$ in $\mathrm{Cd}$ and $\mathrm{Zn}$ cases), thus explaining the peak height.

\section{CONCLUSION}

A very promising system measuring continuously the gaseous emissions of metallic pollutants during thermal treatment was developed. It is composed of an ICP spectrometer coupled to the outlet of a high temperature combustion system, and it includes a calibration device in order to obtain quantitative measurements of the vaporized heavy metals, as long as the measured concentration is higher than the detection 
limit (about $10 \mu \mathrm{g} / \mathrm{m}^{3}$ ). This technique was implemented in the case of lab-scale fluid bed and fixed bed reactors but it can be applied to any high temperature process (from room temperature to $900^{\circ} \mathrm{C}$ ), where it could be useful for controlling metallic emissions. It is a versatile tool which could be easily adapted to:

- the measurement of any metallic emissions (heavy metals, alkaline metals, etc.);

- various kinds of waste (municipal waste, sludge from water treatment plant, biomass);

- any high temperature process (incineration, coal combustion, mineral treatment, plasma process, etc.)

Moreover, the development of such an on-line monitoring device could lead to a possible standardization of the measurement procedure of metals in fumes.

\section{ACKNOWLEDGEMENT}

The authors are thankful to ADEME (Agence de l'Environnement et de la Maîtrise de l'Energie), and Région Languedoc-Roussillon for financial support.

\section{REFERENCE}

1. R. Oikari, V. Hayrinen, T. Parviainen and R.: Applied Spectroscopy, 55, 1469-1477(2001).

2. S.G. Buckley, H.A. Johnsen, K.R. Hencken and D.W. Hahn: Waste Management, 20, 455-462 (2000).
3. R.E. Neuhauser, U. Panne and R. Niessner: Analytical Chemistry Acta, 392, 47-54(1999).

4. P.P..Woskov, K..Hadidi, P..Thomas, K..Green and G..Flores: Waste Management, 20, 395-402 (2000).

5. C. Hélou : Analyse d'élements traces dans les gaz par spectroscopie d'emission utilisant un plasma induit par haute frequence, Thèse de doctorat de l'Université de Lyon. (1981).

6. C. Trassy, F. Petit, R. Diemiaszonek and P. Fauchais: High Temperature Materials and Processes, 2, 449-460 (1997).

7. D.J. Poole, V.N. Sharifi, J. Swithenbank and D.A rdelt: Journal of Analytical Atomic Spectrometry, 20, 932-938 (2005).

8. S. Abanades, D. Gauthier, G. Flamant and C. Trassy: Combustion Science and Technology, 4, 459-474 (2003).

9. J. Liu, S. Abanades, D. Gauthier, G. Flamant, C. Zheng and J. Lu : Environmental Sci. \& Technol., 39, 9331-9336 (2005).

10. Q. Falcoz, D. Gauthier, S. Abanades and G. Flamant G. Clean Air, 8, 1-14 (2007).

11. Y.M. Chang, C.Q. Jia, J.W. Graydon and D.W. Kirl: Journal of Hazardous Materials, 50, 629-646 (1996).

12. L.S. Morf, P.H. Brunner and S. Spaun: Management and Research, 18, 4-15 (2000).

13. J. Corella and J.M. Toledo: Journal of Hazardous Materials, 80, (1-3), 81-105 (2000).

14. J.M. Toledo, J. Corella and L.M. Corella: Journal of Hazardous Materials, 126 (1-3), 158-168 (2005). 
